\title{
miR-181d promotes cell proliferation via the IGF1/PI3K/AKT axis in glioma
}

\author{
DONG TANG ${ }^{1}$, WENHONG GAO ${ }^{2}$, JIAN YANG $^{1}$, JUNHUI LIU $^{1}$, JIAN ZHAO $^{1}$, \\ JIAN GE $^{1}$, QIANXUE CHEN ${ }^{1}$ and BAOHUI LIU ${ }^{1}$ \\ ${ }^{1}$ Department of Neurosurgery, Renmin Hospital of Wuhan University, Wuhan, Hubei 430060; ${ }^{2}$ Department of Neurosurgery, \\ Jingzhou Central Hospital, The Second Clinical Medical College, Yangtze University, Jingzhou, Hubei 434020, P.R. China
}

Received May 19, 2019; Accepted April 17, 2020

DOI: $10.3892 / \mathrm{mmr} .2020 .11464$

\begin{abstract}
Glioma is a malignant brain cancer that exhibits high invasive ability and poor prognosis. MicroRNA (miR)-181d has been reported to be involved in the development of glioma. Therefore, the aim of the present study was to investigate whether miR-181d affected cellular progression by influencing the insulin like growth factor (IGF1)/PI3K/AKT axis. Western blot analysis was performed to analyze the expression levels of specific proteins, and a Cell Counting Kit-8 assay was used to assess the proliferative ability of cells. Cell cycle progression and cellular apoptosis were both measured using flow cytometry. The results indicated that miR-181d promoted cellular proliferation and cell cycle progression, while suppressing cellular apoptosis via the IGF1/PI3K/AKT axis. It was demonstrated that the IGF1 and PI3K/AKT inhibitors reversed these observed functions of miR-181d. Furthermore, miR-181d enhanced the growth of glioma xenografts in vivo, promoted cell cycle progression and suppressed cellular apoptosis within glioma xenograft tissues. Therefore, this newly identified miR-181d/IGF1/PI3K/AKT axis may provide novel insights into the pathogenesis of glioma.
\end{abstract}

\section{Introduction}

Glioma is a malignant brain cancer that exhibits high invasiveness, is typically dispersed throughout the brain, blood vessels and their basement membranes, which are rich in extracellular matrix (1-3). The DNA alkylating agent temozolomide, when used in combination with radiation therapy, improves the survival rate in patients with glioma (4). However, previous studies have reported that only $\sim 10 \%$ of patients undergoing

Correspondence to: Dr Qianxue Chen or Dr Baohui Liu, Department of Neurosurgery, Renmin Hospital of Wuhan University, 238 Jiefang Road, Wuchang, Wuhan, Hubei 430060, P.R. China

E-mail: chenqx666@whu.edu.cn

E-mail: whdxliubaohui@163.com

Key words: microRNA-181d, proliferation, cell cycle, apoptosis, glioma, insulin like growth factor 1/PI3K/AKT this therapy can survive for 5 years $(5,6)$. Therefore, it is important to discover novel biomarkers that may be clinically useful in the field of neuro-oncology.

MicroRNAs (miRNAs) are small, non-coding RNAs that are 19-24 nucleotides in length, and when combined with target mRNAs, they can function to post-transcriptionally regulate gene expression $(7,8)$. miRNAs have become a hotspot for research in the field of biology, and an increasing number of studies have identified the underlying mechanism of action for numerous miRNAs (miRs) $(9,10)$. miR-181d is a member of the miR-181 family, which includes miR-181a, miR-181b, miR-181c and miR-181d (11,12). miR-181d is strongly expressed in a wide range of cancer tissues, and it plays an important role in the regulation of tumorigenesis, metastasis and apoptosis $(13,14)$. For example, miR-181d can regulate KRAS proto-oncogene to reduce migration, apoptosis and cell cycle transition in glioma cells (15). In addition, miR-181d downregulates methylguanine-methyltransferase to inhibit cancer migration, and it serves as a common biomarker for human glioblastoma (16). However, it has been suggested that miR-181d is upregulated in gliomas and is an indicator of poor prognosis (17). Based on the evidence that miR-181d acts as a prognostic factor and plays a major role in glioma, the present study performed a number of experiments to further assess the expression and function of miR-181d in glioma.

Insulin like growth factor 1 (IGF1) is a member of a family of proteins involved in the regulation of growth and development, and this protein is structurally and functionally similar to insulin $(18,19)$. IGF1 is a cyclic polypeptide consisting of 70 amino acids and it plays vital roles in cellular proliferation and metabolism (20). In colorectal cancer, IGF1 can modulate cell proliferation and migration (21). Moreover, Wang et al (22) revealed that exposure to an IGF1 inhibitor abrogated cellular proliferation and invasion in glioma.

As an important signal transduction pathway, the $\mathrm{PI} 3 \mathrm{~K} / \mathrm{AKT} / \mathrm{mTOR}$ signaling pathway plays an important role in cellular proliferation, apoptosis and other processes (23). AKT phosphorylates $\mathrm{Bcl} 2$ to initiate apoptosis, inhibits the activity of the proteolytic enzyme Caspase- 9 and activates the apoptotic cascade (24). mTOR is a downstream target gene of PI3K/AKT and this protein is indispensable for tumorigenesis (25). Moreover, brusatol regulates cell proliferation or apoptosis via the PI3K/AKT/mTOR signaling pathway 
in clear cell renal cell carcinoma and hepatocellular carcinoma $(26,27)$. In glioma, oxymatrine induces cell cycle arrest and apoptosis via the PI3K/AKT/mTOR pathway (28). In the present study, a miR-181d mimic, IGF1 inhibitor, PI3K/AKT inhibitor and miR-181d inhibitor were used to treat cells, and the effects of these treatments on cellular proliferation, cell cycle progression and apoptosis were assessed. It was demonstrated that miR-181d promotes cellular proliferation via the $\mathrm{PI} 3 \mathrm{~K} / \mathrm{AK}$ T/mTOR pathway.

\section{Materials and methods}

Cell lines and cell culture. The glioma cell line U251 was obtained from the American Type Culture Collection and cultured in a $37^{\circ} \mathrm{C}$ incubator until the confluence was $\sim 80 \%$. The cells were maintained in DMEM (Gibco; Thermo Fisher Scientific, Inc.) supplemented with 10\% FBS (cat. no. 10270-106; Gibco; Thermo Fisher Scientific, Inc.), $100 \mathrm{U} / \mathrm{ml}$ penicillin and $100 \mathrm{mg} / \mathrm{ml}$ streptomycin at $37^{\circ} \mathrm{C}$ in a humidified atmosphere containing $5 \% \mathrm{CO}_{2}$.

Cell transfection and selection. To detect the functions of miR-181d in glioma cells, the miR-181d mimic, miR-181d inhibitor and a negative control were synthesized from Shanghai GenePharma Co., Ltd. The miR-181d mimic was a double strand that was formed using a mature miR-181d sequence and the complementary sequence (5'-AACAUUCAU UGUUGUCGGUGGGU-3'), while the miR-181d inhibitor was a single strand consisting of the complementary sequence of the mature miR-181d sequence (5'-UUGUAAGUAACAACA GCCACCCA-3'). The transfection was performed using $5 \mu \mathrm{l}$ Lipofectamine $^{\circledR} 2000$ reagent (Invitrogen; Thermo Fisher Scientific, Inc.) and $30 \mathrm{nM}$ miR-181d mimic, $50 \mathrm{nM}$ miR-181d inhibitor or $30 \mathrm{nM}$ negative control that was diluted into $250 \mu \mathrm{l}$ Opti-MEM/Reduced serum medium (Thermo Fisher Scientific, Inc.). At $48 \mathrm{~h}$ post-transfection, the cells were maintained in $400 \mu \mathrm{g} / \mathrm{ml}$ Geneticin (cat. no. G418; Thermo Fisher Scientific, Inc.) to select the cell lines that were stably expressing the miR-181d mimic or miR-181d inhibitor.

Western blot analysis. U251 cells at a density of $70 \%$ were washed twice with $100 \mathrm{ml}$ pre-cooled 1X PBS, and RIPA buffer (Beyotime Institute of Biotechnology) containing phosphatase inhibitor was then added. The cells were lysed on ice, centrifuged at $12,000 \mathrm{x}$ g for $10 \mathrm{~min}$ at $4^{\circ} \mathrm{C}$ and the supernatant containing the desired protein was obtained. The xenograft tissues were also lysed using RIPA to obtain total proteins. Total proteins were quantified using the bicinchoninic acid method and the absorbance was measured at $562 \mathrm{~nm}$. A total of $20 \mu \mathrm{g}$ per lane of total protein were separated by $120 \mathrm{~V}$ electrophoresis on a $12 \%$ SDS-PAGE for $50 \mathrm{~min}$. The blots were then transferred to PVDF membranes (EMD Millipore) at $90 \mathrm{~V}$ for $50 \mathrm{~min}$. After blocking with 5\% skimmed milk at room temperature for $1 \mathrm{~h}$, the membranes were incubated with the primary antibodies overnight at $4^{\circ} \mathrm{C}$ with GAPDH as the internal reference. After washing three times with TBS-Tween $20(0.05 \%)$, the membranes were incubated with horseradish peroxidase-conjugated goat anti-rabbit $\mathrm{IgG}$ at room temperature for $1 \mathrm{~h}$. Equal amounts $(500 \mu \mathrm{l})$ of Electrochemical Luminescence Kit (ECL) illuminating liquids A and B (Pierce; Thermo Fisher Scientific, Inc.) were mixed and used to visualize the signal on a Molecular Imager ChemiDoc XRS System (Bio-Rad Laboratories, Inc.) using Tanon MP v1.0.2.0 software (Tanon Science and Technology Co.). The primary antibodies and the secondary antibody are presented in Table I.

Cell Counting Kit-8 (CCK-8) assay. CCK-8 (Bioswamp Life Science Lab) was used to determine cell proliferation according to the manufacturer's instructions. A total of $3 \times 10^{3} \mathrm{U} 251$ cells were seeded into 96-well plates and cultured for $24 \mathrm{~h}$ at $37^{\circ} \mathrm{C}$ in a humidified atmosphere containing $5 \% \mathrm{CO}_{2}$. Subsequently, the IGF1 inhibitor (Linsitinib; OSI-906, SelleckChemicals) or the PI3K/AKT inhibitor (LY294002, Sigma-Aldrich; Merck $\mathrm{KGaA}$ ) were added to the cells and incubated for $24 \mathrm{~h}$ at room temperature. The CCK- 8 solution $(10 \mu \mathrm{l})$ was added to the cells, which were then cultured for $4 \mathrm{~h}$ at $37^{\circ} \mathrm{C}$. The absorbance at $450 \mathrm{~nm}$ was subsequently measured using an ELISA plate reader (BioTek Instruments, Inc.).

Cell cycle. Cell cycle progression was detected by flow cytometry. The cells transfected with mir-181d mimic, IGF1 inhibitor, PI3K/AKT inhibitor or mir-181d inhibitor were suspended in a PBS solution containing 10\% FBS, and then the cells were fixed in absolute ethyl ethanol at room temperature for $24 \mathrm{~h}$. Next, the samples were centrifuged at 3,000 x g for $30 \mathrm{sec}$ at room temperature and the supernatant was discarded. Subsequently, the cell pellet was suspended in $100 \mu \mathrm{l}$ RNase A solution $(1 \mathrm{mg} / \mathrm{ml})$ and digested at $37^{\circ} \mathrm{C}$ for $10 \mathrm{~min}$. Cells were then stained at room temperature for $10 \mathrm{~min}$ using $400 \mu \mathrm{l}$ propidium iodide (PI, $50 \mu \mathrm{g} / \mathrm{ml}$, Nanjing KeyGen Biotech Co., Ltd.) in the dark and analyzed by a FC500 MCL flow cytometer (Beckman Coulter) using MODFIT LT 2.0 (Verity Software House, Inc.). The proportion of cells in $G_{0} / G_{1}, S$ and $G_{2} / M$ stages was evaluated, and all procedures were performed in triplicate.

Cell apoptosis. Cellular apoptosis was detected using the Annexin-V/PI detection kit (Nanjing KeyGen Biotech Co., Ltd.) according to the manufacturer's protocol. The transfected cells were suspended and centrifuged at 1,000 x $\mathrm{g}$ for $5 \mathrm{~min}$ at room temperature. The supernatant was then removed, and the cells were resuspended in $200 \mu \mathrm{l}$ binding buffer. The cells were stained with $10 \mu \mathrm{l}$ Annexin V-FITC and $10 \mu \mathrm{l} \mathrm{PI}$ and then incubated for $30 \mathrm{~min}$ at $4^{\circ} \mathrm{C}$ in the dark. Cellular apoptosis was detected under a FC500 MCL flow cytometer (Beckman Coulter, Inc.) and analyzed using CXP Analysis 2.0 software (Beckman Coulter, Inc.). The apoptotic rate was calculated by the percentage of early and late apoptotic cells.

Animal study. Thirty male BALB/C nude mice (age, 4-6 weeks, weight, $20 \mathrm{~g}$ ) were purchased from the Experimental Animal Center of the Chinese Academy of Sciences and were prepared for this experiment. All mice were housed at $22 \pm 2^{\circ} \mathrm{C}$, $45-60 \%$ humidity and a $12 \mathrm{~h}$ light/day cycle. All mice received food and water ad libitum. For the xenograft tumor model, $5 \times 10^{6} \mathrm{U} 251$ cells were injected subcutaneously into the axilla of the nude mice. After the cells were cultured to the size of $\sim 3 \mathrm{~mm}$, the nude mice were randomly divided into five groups for drug treatment three times a week for a total of three weeks. The five groups included the control, overexpression 
Table I. Details of the antibodies used in the present study.

\begin{tabular}{|c|c|c|c|c|}
\hline Antibodies & Species & Company & Cat. no. & Dilution \\
\hline IGF1 & Rabbit & Abcam & Ab9572 & $1: 10,000$ \\
\hline PI3K & Rabbit & Abcam & Ab191606 & $1: 1,000$ \\
\hline $\mathrm{p}-\mathrm{PI} 3 \mathrm{~K}$ & Rabbit & Abcam & Ab182651 & $1: 1,000$ \\
\hline $\mathrm{AKT}$ & Rabbit & Abcam & Ab8805 & $1: 500$ \\
\hline $\mathrm{p}-\mathrm{AKT}$ & Rabbit & Abcam & Ab38449 & $1: 1,000$ \\
\hline mTOR & Rabbit & Abcam & Ab2732 & $1: 2,000$ \\
\hline p-mTOR & Rabbit & Abcam & Ab109268 & $1: 5,000$ \\
\hline $\mathrm{Bcl} 2$ & Rabbit & Abcam & Ab182858 & $1: 2,000$ \\
\hline Caspase-3 & Rabbit & Abcam & Ab13847 & $1: 500$ \\
\hline Caspase- 8 & Rabbit & Abcam & Ab25901 & $1: 1,000$ \\
\hline Caspase-9 & Rabbit & Abcam & Ab202068 & $1: 2,000$ \\
\hline Cyclin D & Rabbit & Abcam & Ab16663 & $1: 200$ \\
\hline Cyclin E & Rabbit & Abcam & Ab33911 & $1: 2,000$ \\
\hline Ki67 & Rabbit & Abcam & Ab92742 & $1: 5,000$ \\
\hline IDH-1R & Rabbit & Abcam & Ab94571 & $1: 1,000$ \\
\hline IGFB2 & Rabbit & Abcam & Ab91404 & $1: 500$ \\
\hline PTEN & Rabbit & Abcam & Ab32199 & $1: 10,000$ \\
\hline TERT & Rabbit & Abcam & Ab191523 & $1: 1,000$ \\
\hline GAPDH & Rabbit & CST & 2118 & $1: 1,000$ \\
\hline Goat anti rabbit IgG & Goat & Bio-swamp life science & PAB150011 & $1: 10,000$ \\
\hline
\end{tabular}

CST, Cell Signaling Technology, Inc.; p-, phosphorylated; TERT, telomerase reverse transcriptase; IDH-1R, isocitrate dehydrogenase 1 receptor; IGFBP2, insulin like growth factor binding protein 2; IGF1, Insulin like growth factor 1 .

(10 $\mu \mathrm{g}$ miR-181d-mimic by injection), interference $(10 \mu \mathrm{g}$ miR-181d-inhibitor by injection), IGF-1 inhibitor $(20 \mathrm{mg} / \mathrm{kg} /$ day Linsitinib, by gavage)and PI3K/AKT inhibitor $(100 \mathrm{mg} / \mathrm{kg}$ LY294002, by gavage) groups.

After the xenograft model was established, the length (L) and width $(\mathrm{W})$ of the subcutaneous tumors were measured every 2 days using a vernier caliper. Tumor volume was calculated using the formula $\left(\mathrm{Lx} \mathrm{W}^{2}\right) / 2$. On the 28th day after seeding the cells, the mice were sacrificed to obtain tumor specimens. The experiment was performed according to the revised guidelines for the Care and Use of Experimental Animals (National Institutes of Health) (29). The experimental program has been approved by the Ethics Committee of Renmin Hospital of Wuhan University (Hubei, China).

Statistical analysis. The data were analyzed using SPSS 16.0 software (IBM Corp.) and GraphPad Prism software (version 6; GraphPad Software, Inc.) and are presented as the mean \pm SD. Unpaired Student's t-test and one-way ANOVA followed by Bonferroni post-hoc test were applied to determine the significance of differences among the various groups. $\mathrm{P}<0.05$ was considered to indicate a statistically significant difference. All experiments were performed in triplicate.

\section{Results}

miR-181d promotes cellular proliferation via the PI3K/AKT/mTOR signaling pathway in U251 cells. To investigate the functions of miR-181d in glioma cells, a
miR-181d mimic, a miR-181d inhibitor and a negative control were synthesized. In addition, IGF1 and PI3K/AKT inhibitors were used to examine whether miR-181d regulated cell proliferation via the PI3K/AKT/mTOR pathway. U251 cells were transfected or treated with miR-181d mimic, IGF1 inhibitor, PI3K/AKT inhibitor or miR-181d inhibitor (Fig. S1). After evaluating the expression of IGF1, it was identified that miR-181d mimic significantly increased $(\mathrm{P}=0.0039)$ its expression, while the IGF1, PI3K/AKT and miR-181d inhibitors significantly reduced $(\mathrm{P}=0.0001$, $\mathrm{P}=0.0002$ and $\mathrm{P}=0.0003$, respectively) the expression of IGF1 (Fig. 1A).

The proliferative abilities of the cells were calculated, and it was demonstrated that proliferation was increased after exposure to the miR-181d mimic $(\mathrm{P}=0.0001)$, but was inhibited by treatment with the IGF1, PI3K/AKT and miR-181d inhibitors $(\mathrm{P}<0.0001$; Fig. 1B).

In addition, western blot analysis indicated that the miR-181d mimic promoted the expression levels of phosphorylated (p)-PI3K, p-AKT and p-mTOR $(\mathrm{P}=0.042, \mathrm{P}=0.0127$ and $\mathrm{P}=0.0058)$, while the expression levels of PI3K, AKT and mTOR were unchanged in U251 cells. However, treatment with the IGF1 inhibitor $(\mathrm{P}=0.0028, \mathrm{P}<0.0001$ and $\mathrm{P}=0.0147$, respectively), the $\mathrm{PI} 3 \mathrm{~K} / \mathrm{AKT}$ inhibitor $(\mathrm{P}=0.0011, \mathrm{P}<0.0001$ and $\mathrm{P}=0.0055$, respectively) and the miR-181d inhibitor $(\mathrm{P}=0.0014, \mathrm{P}=0.0003$ and $\mathrm{P}=0.0009$, respectively) suppressed the expression levels of p-PI3K, p-AKT and p-mTOR (Fig. 1C), thus suggesting that miR-181d regulates cellular proliferation via the PI3K/AKT/mTOR pathway. 
A

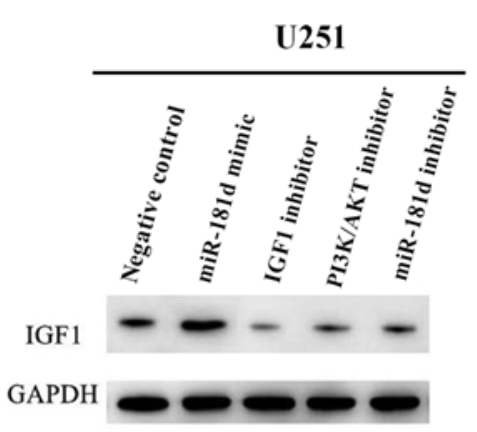

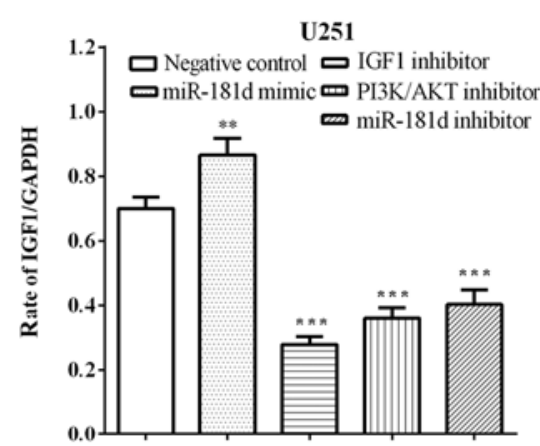

B

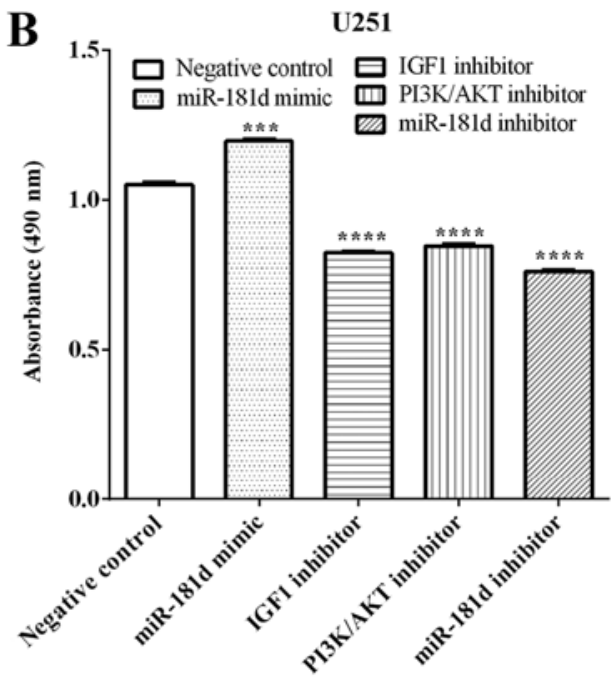

U251
C

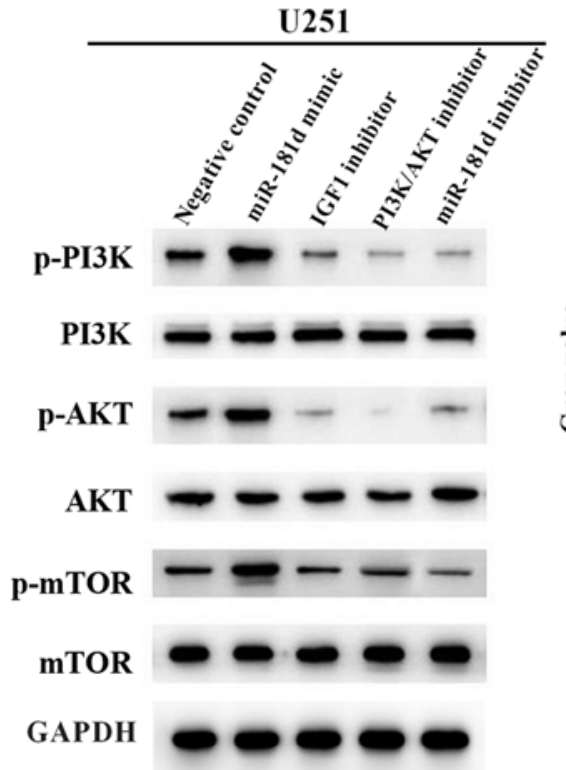

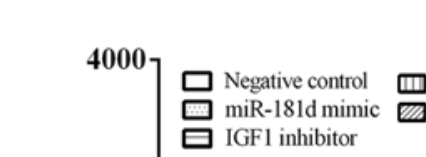

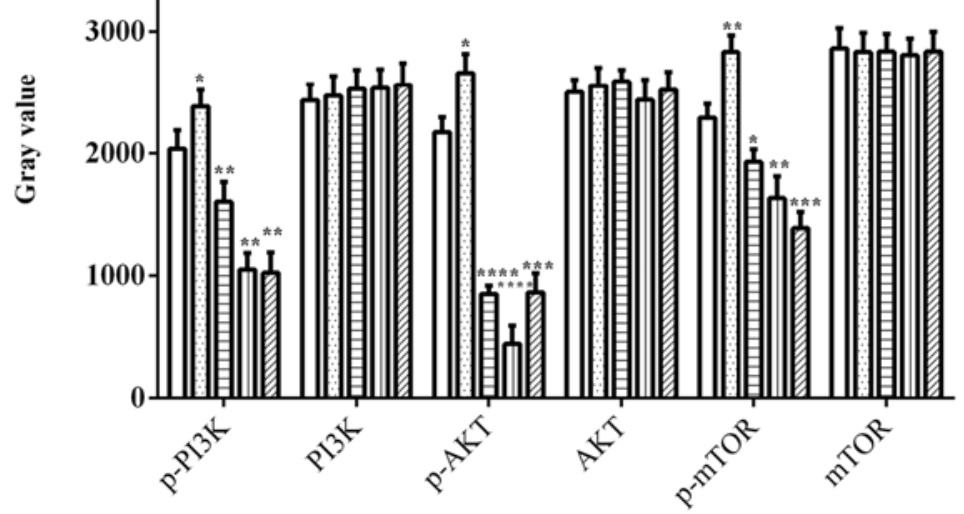

Figure 1. miR-181d promotes proliferation via the PI3K/AKT/mTOR signal pathway in U251 cells. (A) miR-181d enhanced the expression of IGF1, and treatment with the IGF1 inhibitor, PI3K/AKT inhibitor and miR-181d inhibitor reduced the expression of IGF1. (B) miR-181d mimic increased cellular proliferation, while treatment with the IGF1, PI3K/AKT or miR-181d inhibitors decreased proliferation. (C) miR-181d regulated cellular proliferation via the PI3K/AKT/mTOR pathway. ${ }^{*} \mathrm{P}<0.05,{ }^{* *} \mathrm{P}<0.01,{ }^{* * *} \mathrm{P}<0.001,{ }^{* * * *} \mathrm{P}<0.0001$ vs. negative control. miR, microRNA; IGF1, insulin like growth factor 1 ; p-, phosphorylated.

miR-181d promotes cell cycle progression via the IGF1/PI3K/AKT axis in U251 cells. The cell cycle profile of U251 cells was detected using a flow cytometry-based assay. The proportions of cells in the $\mathrm{G}_{0} / \mathrm{G}_{1}$ phase after treatment with negative control, miR-181d mimic, IGF1 inhibitor, $\mathrm{PI} 3 \mathrm{~K} / \mathrm{AKT}$ inhibitor and $\mathrm{miR}-181 \mathrm{~d}$ inhibitor were $43.04 \pm 1.43$, $39.57 \pm 0.97,64.92 \pm 1.85,60.16 \pm 2.47$ and $66.65 \pm 3.46 \%$, respectively. Under these same conditions, the proportions in $\mathrm{S}$ phase were $40.21 \pm 1.50,43.61 \pm 1.03,25.38 \pm 2.37,28.49 \pm 1.64$ and $24.79 \pm 2.32 \%$, while the proportions in $\mathrm{G}_{2} / \mathrm{M}$ phase were $16.75 \pm 1.55,16.82 \pm 1.45,9.70 \pm 1.05,11.35 \pm 1.42$ and $8.56 \pm 0.92 \%$, respectively (Fig. 2A). Compared with the negative control, the proportion of $\mathrm{G}_{0} / \mathrm{G}_{1}$ phase cells in the miR-181d mimic group was decreased significant $(\mathrm{P}=0.0254)$, while the proportions in the groups treated with the IGF1, PI3K/AKT and miR-181d inhibitors were significantly increased $(\mathrm{P}<0.0001, \mathrm{P}=0.0005$ and $\mathrm{P}=0.0004$, respectively). In $\mathrm{S}$ phase, compared with the negative control, the proportion of cells was significantly increased in the miR-181d mimic group $(\mathrm{P}=0.0318)$, while the proportions in the groups treated with the IGF1, PI3K/AKT and miR-181d inhibitors were significantly reduced $(\mathrm{P}=0.0008$ for all; Fig. 2B).

Proteins associated with cell cycle, including Ki67, isocitrate dehydrogenase 1 receptor (IDH-1R), insulin like growth factor binding protein 2 (IGFBP2), PTEN and telomerase reverse transcriptase (TERT), were assessed by western blotting. The expression levels of Ki67 ( $\mathrm{P}=0.0023)$, IDH-1R $(\mathrm{P}=0.0019)$, IGFBP2 $(\mathrm{P}=0.0065)$ and TERT $(\mathrm{P}=0.0010)$ were enhanced by miR-181d mimic, while the expression of PTEN was inhibited $(\mathrm{P}=0.0015)$. However, the expression levels of Ki67 ( $\mathrm{P}=0.0002, \mathrm{P}<0.0001$ and $\mathrm{P}=0.0004$, respectively), IDH-1R ( $\mathrm{P}=0.0003, \mathrm{P}=0.0008$ and $\mathrm{P}=0.0004$, respectively), IGFBP2 $(\mathrm{P}=0.0002, \mathrm{P}=0.0002$ and $\mathrm{P}=0.0005$, respectively) and TERT $(\mathrm{P}=0.0007, \mathrm{P}=0.0006$ and $\mathrm{P}=0.0002$, respectively) were suppressed, but $\mathrm{PTEN}$ expression $(\mathrm{P}<0.0001, \mathrm{P}=0.0006$ and $\mathrm{P}=0.0004$, respectively) was increased by treatment with the IGF1 inhibitor, PI3K/AKT inhibitor and miR-181d inhibitor (Fig. 2C). Collectively, these results suggested that the cell 
A
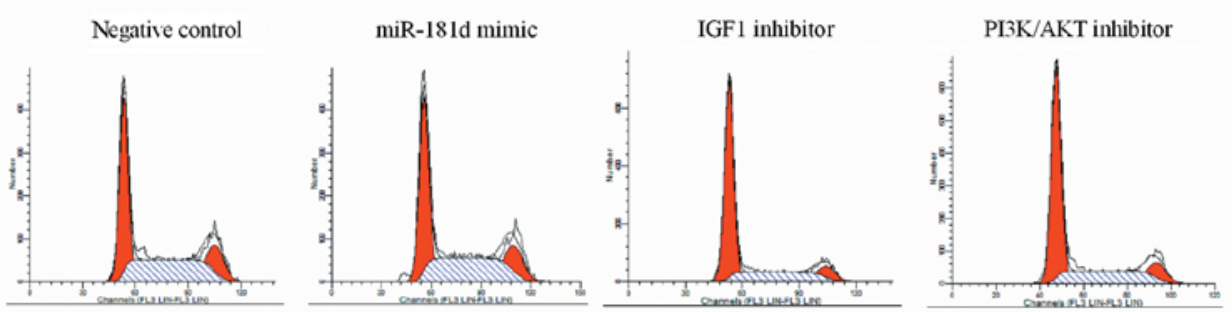

miR-181d inhibitor

B

C
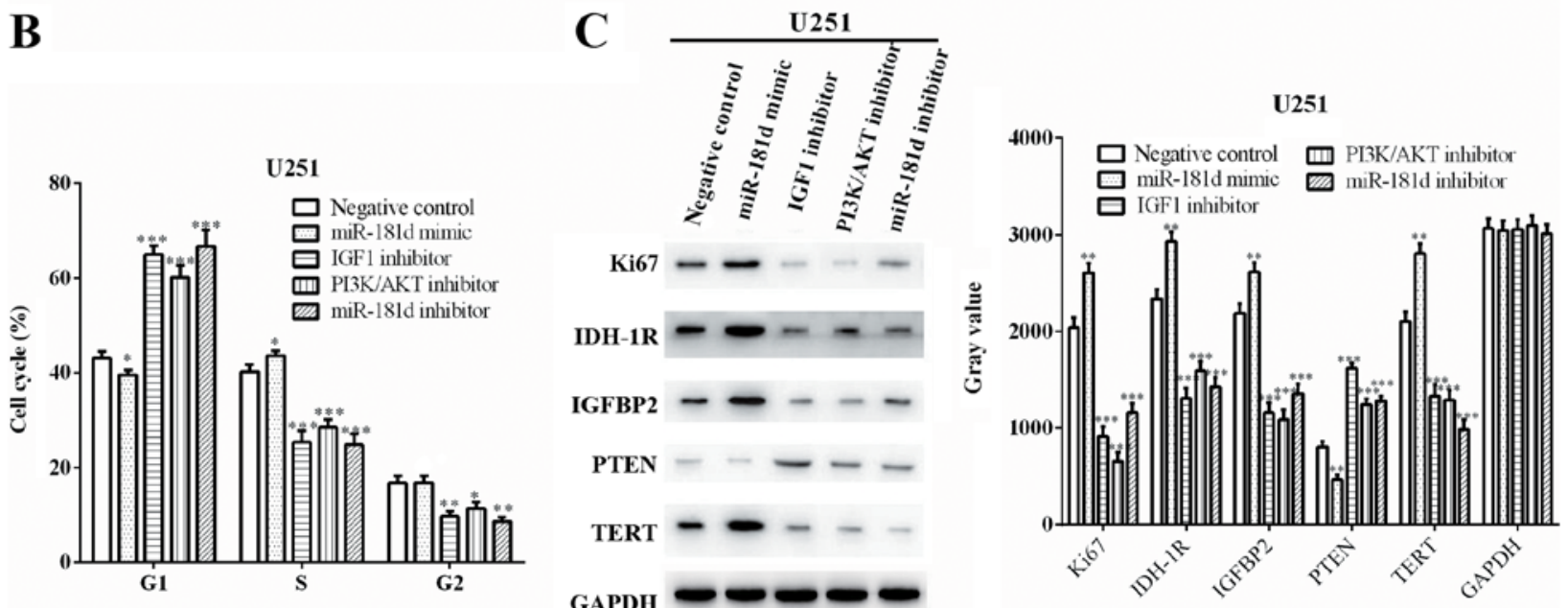

Figure 2. miR-181d promotes cell cycle progression via the IGF1/PI3K/AKT axis in U251 cells (A) Distribution of cells within the stages of the cell cycle was determined. (B) Cell distribution ratio for each period. (C) miR-181d mimic, IGF1 inhibitor, PI3K/AKT inhibitor and miR-181d inhibitor regulated the expression levels of Ki67, IDH-1R, IGFBP2, TERT and PTEN. ${ }^{*} \mathrm{P}<0.05,{ }^{* *} \mathrm{P}<0.01,{ }^{*} * * \mathrm{P}<0.001$ vs. negative control. miR, microRNA; IGF1, insulin like growth factor 1; TERT, telomerase reverse transcriptase; IDH-1R, isocitrate dehydrogenase 1 receptor; IGFBP2, insulin like growth factor binding protein 2.

A
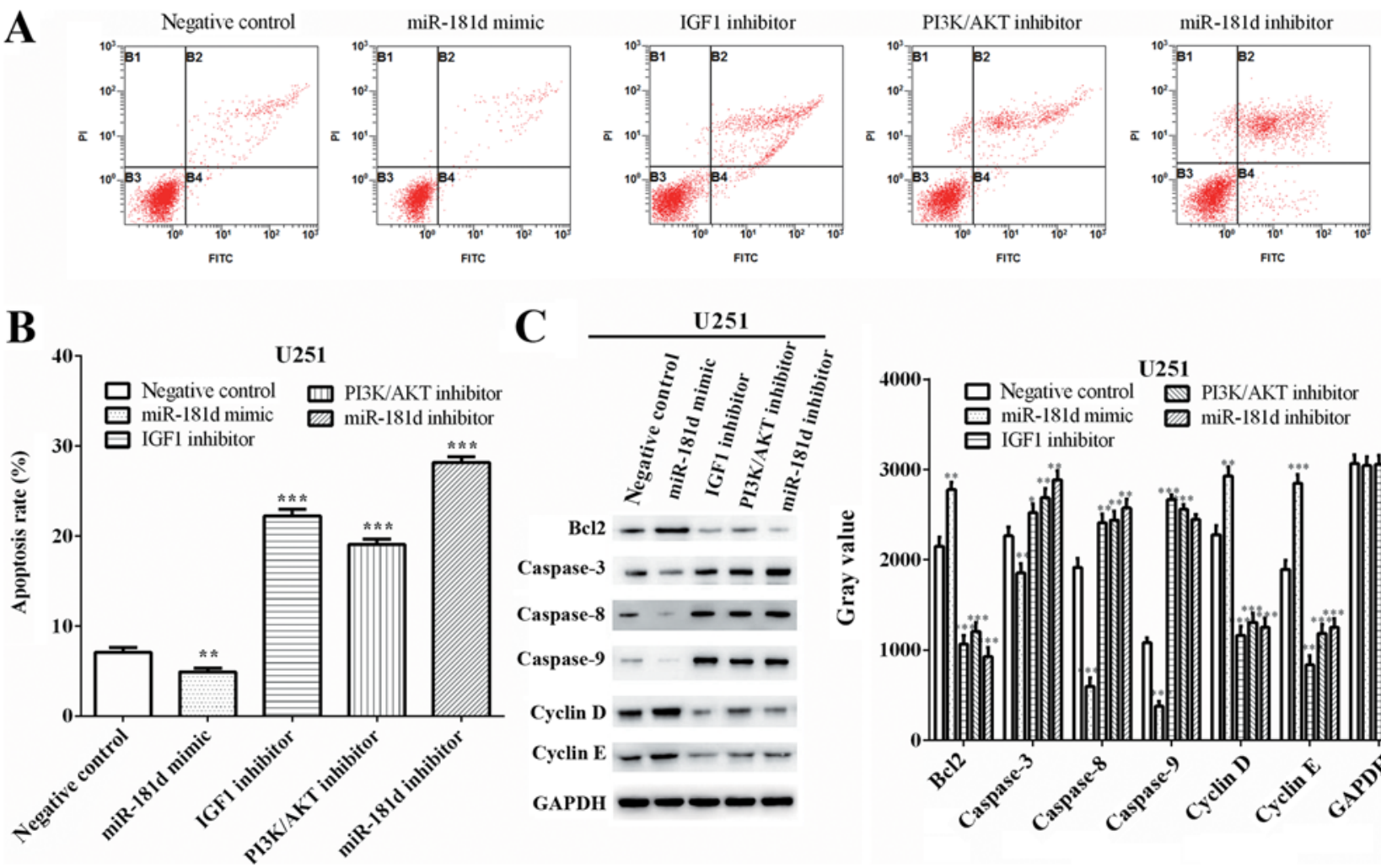

C
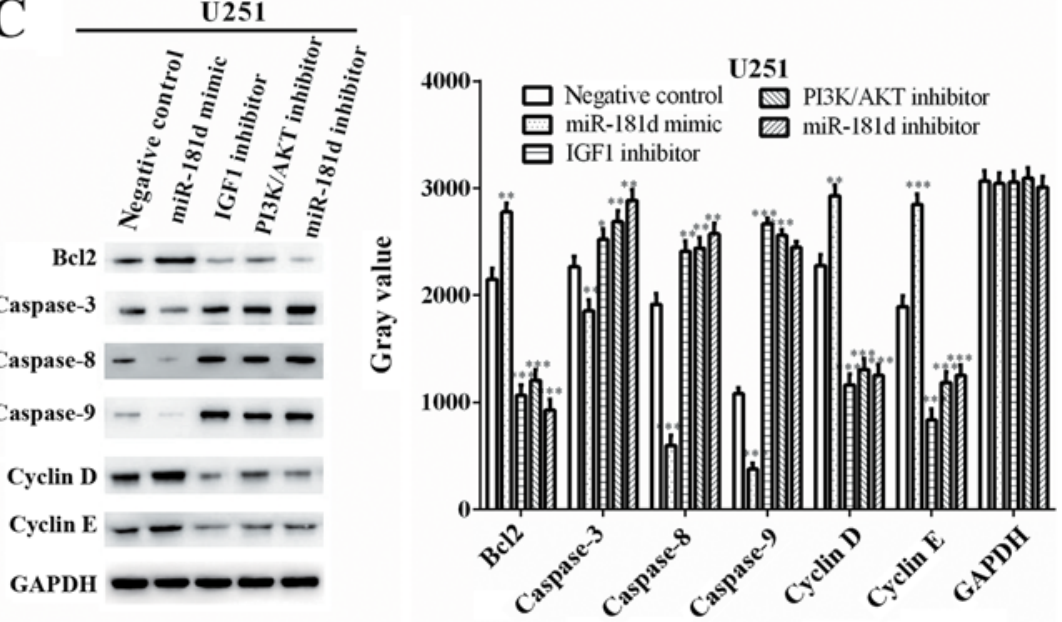

Figure 3. miR-181d inhibits cell apoptosis via the IGF1/PI3K/AKT axis in U251 cells. (A) PI and Annexin-V double staining and flow cytometric analysis was used to detect apoptosis in U251 cells. (B) Compared with the negative control, the apoptotic rate was reduced by miR-181d, but was increased by treatment with the IGF1, PI3K/AKT and miR-181d inhibitors. (C) miR-181d mimic, IGF1 inhibitor, PI3K/AKT inhibitor and miR-181d inhibitor mediated the expression levels of Bcl2, Cyclin D, Cyclin E, Caspase-3, Caspase- 8 and Caspase-9 in U251 cells. ${ }^{*} \mathrm{P}<0.05,{ }^{* *} \mathrm{P}<0.01,{ }^{* * *} \mathrm{P}<0.001$. PI, propidium iodide; miR, microRNA; IGF1, insulin like growth factor 1 . 

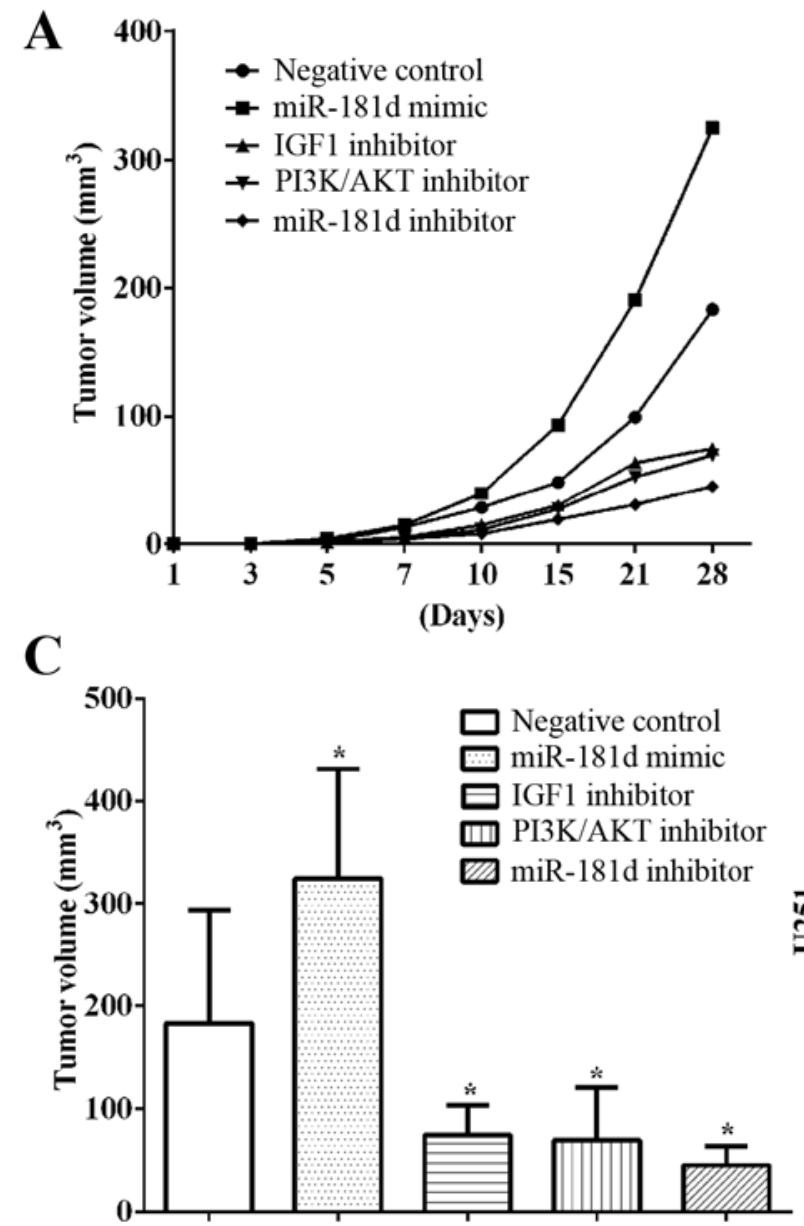
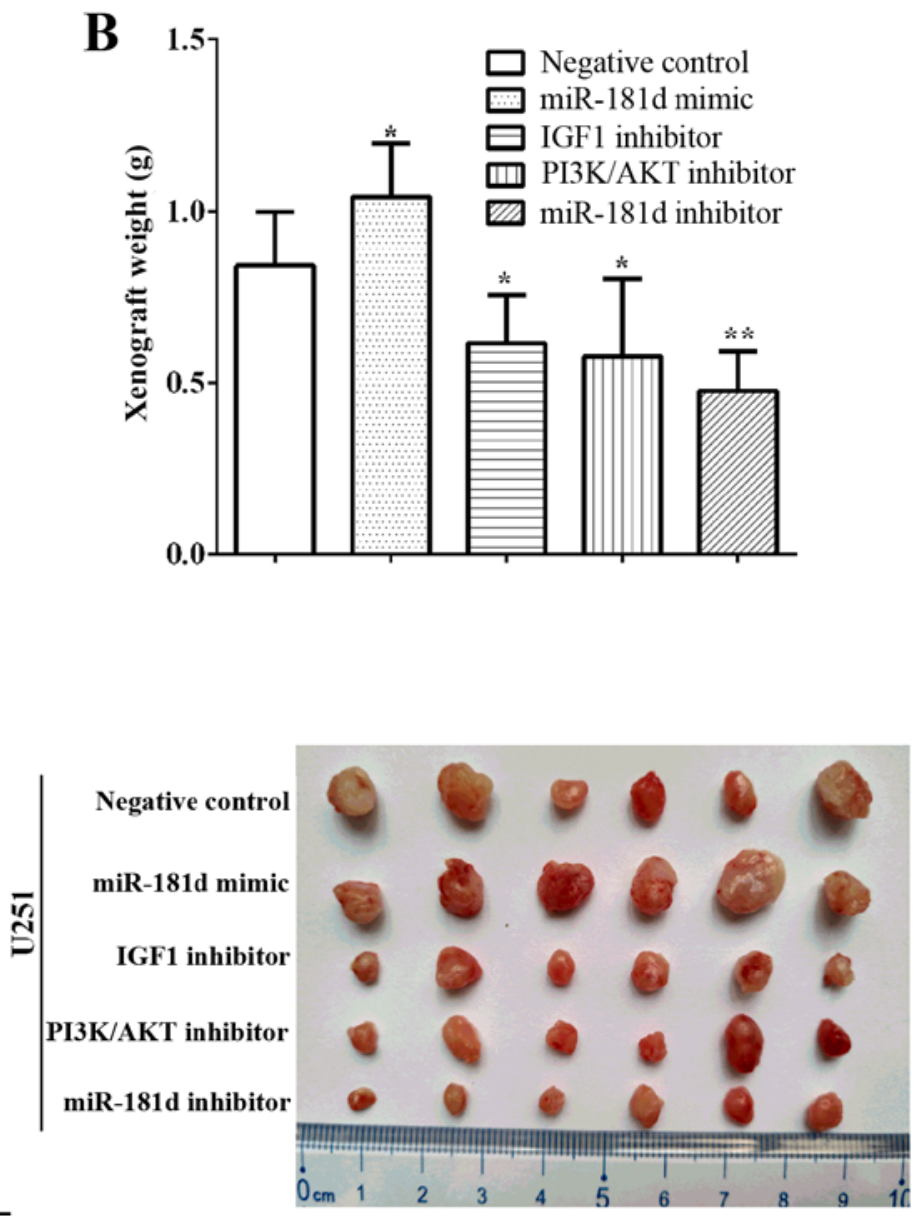

Figure 4. miR-181d enhances the growth of glioma xenografts in vivo. (A) Growth of xenografts was promoted by the miR-181d mimic, but was inhibited by treatment with the IGF1, PI3K/AKT and miR-181d inhibitors. (B) Weights of the xenografts were determined. (C) Xenograft volumes were evaluated. " $\mathrm{P}<0.05$, ${ }^{* *} \mathrm{P}<0.01$ vs. negative control. miR, microRNA; IGF1, insulin like growth factor 1.

cycle was promoted by miR-181d via the IGF1/PI3K/AKT pathway in U251 cells.

miR-181d inhibits cellular apoptosis via the IGF1/PI3K/AKT axis in $U 251$ cells. Flow cytometry was performed to investigate the influence of miR-181d on apoptosis in U251 cells. The apoptotic rates for the negative control, miR-181d mimic, IGF1 inhibitor, PI3K/AKT inhibitor and miR-181d inhibitor groups were $7.08 \pm 0.56,4.90 \pm 0.43,22.22 \pm 0.74,19.07 \pm 0.58$ and 28.18 \pm 0.65 , respectively (Fig. 3A). Compared with the negative control, the apoptotic rate was reduced $(\mathrm{P}=0.0059)$ by the miR-181d mimic, but was increased by treatment with the IGF1, PI3K/AKT and miR-181d inhibitors $(\mathrm{P}<0.0001$ for all; Fig. 3B).

Apoptotic-related proteins were assessed by western blotting in U251 cells. It was indicated that the miR-181d mimic increased the expression levels of Bcl2, Cyclin D and Cyclin E ( $\mathrm{P}=0.0011, \mathrm{P}=0.0013$ and $\mathrm{P}=0.0003$, respectively), while it inhibited the expression levels of Caspase-3, Caspase- 8 and Caspase-9 $(\mathrm{P}=0.0073, \mathrm{P}<0.0001$ and $\mathrm{P}<0.0001$, respectively) in U251 cells. However, cells transfected or treated with IGF1 inhibitor $(\mathrm{P}=0.0002, \mathrm{P}=0.0002$ and $\mathrm{P}=0.0002$; and $\mathrm{P}=0.0354, \mathrm{P}=0.0038$ and $\mathrm{P}<0.0001$, respectively), $\mathrm{PI} 3 \mathrm{~K} / \mathrm{AKT}$ inhibitor $(\mathrm{P}=0.0004, \mathrm{P}=0.0003$ and $\mathrm{P}=0.0010$; and $\mathrm{P}=0.0067$, $\mathrm{P}=0.0030$ and $\mathrm{P}<0.0001$, respectively) and miR-181d inhibitor
$(\mathrm{P}=0.0001, \mathrm{P}=0.0002$ and $\mathrm{P}=0.0014$; and $\mathrm{P}=0.0016, \mathrm{P}=0.0013$ and $\mathrm{P}<0.0001$, respectively) exhibited the opposite trend (Fig. 3C). Thus, the results suggested that miR-181d inhibited cellular apoptosis via the IGF1/PI3K/AKT axis in U251 cells.

miR-181d enhances glioma xenograft growth in vivo. To determine if $\mathrm{miR}-181 \mathrm{~d}$ regulated the growth of glioma xenografts via the IGF1/PI3K/AKT axis, U251 cells were subcutaneously injected into nude mice. Xenograft growth was promoted by the miR-181d mimic, but was inhibited by treatment with the IGF1, PI3K/AKT and miR-181d inhibitors (Fig. 4A). Moreover, xenograft weights were calculated, and it was observed that the weights in the miR-181d mimic group were higher compared with the negative control $(\mathrm{P}=0.0471)$. The xenograft weights were also decreased in the IGF1 inhibitor $(\mathrm{P}=0.0430), \mathrm{PI} 3 \mathrm{~K} / \mathrm{AKT}$ inhibitor $(\mathrm{P}=0.0459)$ and miR-181d inhibitor $(\mathrm{P}=0.0232)$ groups $(\mathrm{Fig} .4 \mathrm{~B})$. In addition, the xenograft volumes was significantly increased in the miR-181d mimic group $(\mathrm{P}=0.0479)$, but significantly decreased in the IGF1 inhibitor $(\mathrm{P}=0.0267), \mathrm{PI} K \mathrm{~K} / \mathrm{AKT}$ inhibitor $(\mathrm{P}=0.0411)$ and miR-181d inhibitor groups $(\mathrm{P}=0.0011)$ compared with the negative group (Fig. 4C). The maximum diameter of the tumors in the miR-181d mimic group was higher compared with the negative control group, while those in the IGF1 inhibitor and miR-181d inhibitor groups were lower (Fig. S2). 
A
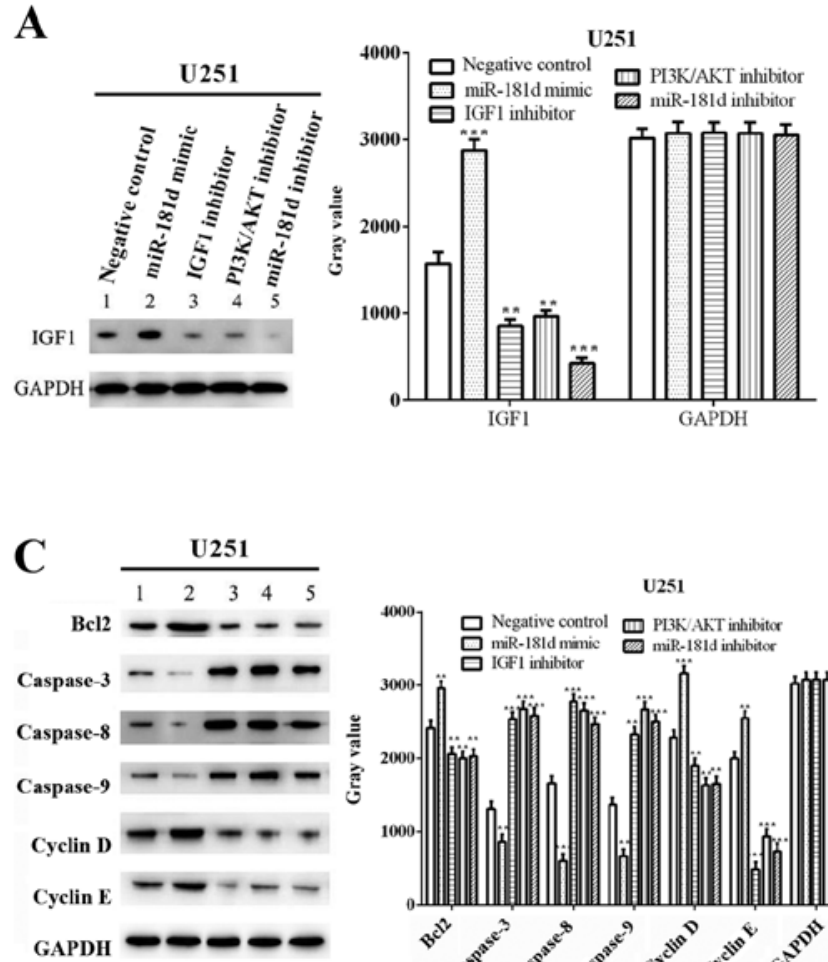

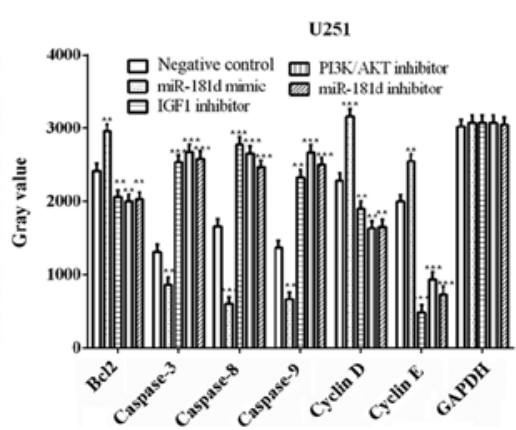

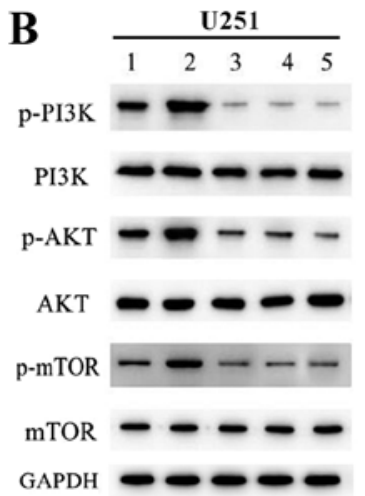

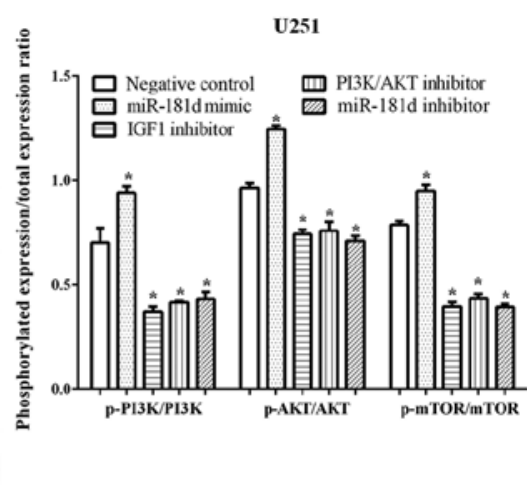

D

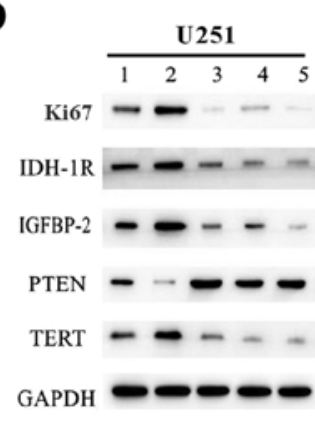

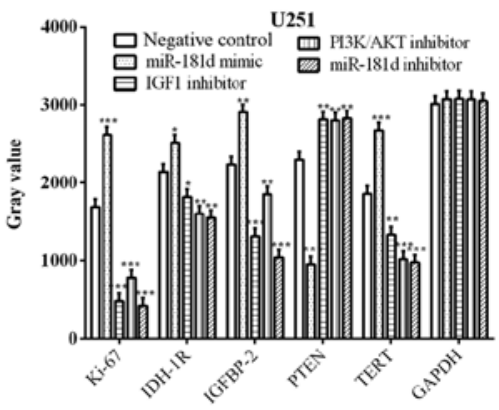

Figure 5. miR-181d promotes cell cycle progression and suppresses cellular apoptosis in glioma xenograft tissues. (A) miR-181d mimic enhanced the expression of IGF1, while treatment with the IGF1, PI3K/AKT and miR-181d inhibitors reduced the expression of IGF1. (B) miR-181d mimic enhanced the $\mathrm{PI} 3 \mathrm{~K} / \mathrm{AKT} / \mathrm{mTOR}$ pathway, while this pathway was inhibited by treatment with the IGF1 inhibitor, PI3K/AKT inhibitor and miR-181d inhibitor. (C) miR-181d decreased cellular apoptosis in glioma xenograft tissues via the IGF1/PI3K/AKT axis. (D) miR-181d promoted cell cycle progression in glioma xenograft tissues via the IGF1/PI3K/AKT axis. ${ }^{*} \mathrm{P}<0.05,{ }^{* *} \mathrm{P}<0.01,{ }^{* * * *} \mathrm{P}<0.001$ vs. negative control. miR, microRNA; IGF1, insulin like growth factor $1 ;$ p-, phosphorylated; TERT, telomerase reverse transcriptase; IDH-1R, isocitrate dehydrogenase 1 receptor; IGFBP2, insulin like growth factor binding protein 2.

miR-181d promotes cell cycle progression and suppresses cellular apoptosis in glioma xenograft tissues. To assess whether miR-181d mediated cell cycle progression via the IGF1/PI3K/AKT axis, the xenograft tissues were lysed using RIPA to obtain total proteins. Similar to the in vitro experiments, the miR-181d mimic enhanced the expression of IGF1 ( $\mathrm{P}=0.0002)$, while treatment with the IGF1 inhibitor $(\mathrm{P}=0.0012)$, $\mathrm{PI} 3 \mathrm{~K} / \mathrm{AKT}$ inhibitor $(\mathrm{P}=0.0021)$ and miR-181d inhibitor $(\mathrm{P}=0.0002)$ reduced the expression of IGF1 (Fig. 5A).

With regards to the proteins in the PI3K/AKT/mTOR signaling pathway, the expression levels of p-PI3K, p-AKT and $\mathrm{p}$-mTOR were increased by treatment with the miR-181d mimic $(\mathrm{P}=0.0041, \mathrm{P}=0.0025$ and $\mathrm{P}=0.0224$, respectively). However, these were reduced by treatment with the IGF1 inhibitor $(\mathrm{P}=0.0001, \mathrm{P}=0.0042$ and $\mathrm{P}=0.0003)$, $\mathrm{PI} 3 \mathrm{~K} / \mathrm{AKT}$ inhibitor $(\mathrm{P}=0.0001, \mathrm{P}=0.0061$ and $\mathrm{P}=0.0005)$ and miR-181d inhibitor $(\mathrm{P}=0.0001, \mathrm{P}=0.0020$ and $\mathrm{P}=0.00032$; Fig. 5B).

The proteins associated with apoptosis were evaluated by western blotting. The expression levels of Bcl2, Cyclin D and Cyclin $\mathrm{E}$ were increased $(\mathrm{P}=0.0026, \mathrm{P}=0.0004$ and $\mathrm{P}=0.0025)$, while Caspase- 3 , Caspase- 8 and Caspase- 9 expression levels were decreased $(\mathrm{P}=0.0054, \mathrm{P}=0.0002$ and $\mathrm{P}=0.0010)$ in $\mathrm{U} 251$ cells transfected with miR-181d mimic. In contrast, treatment with the IGF1, PI3K/AKT and miR-181d inhibitors reduced the expression levels of $\mathrm{Bcl} 2(\mathrm{P}=0.0090$, $\mathrm{P}=0.0072$ and $\mathrm{P}=0.0095$, respectively), Cyclin $\mathrm{D}(\mathrm{P}=0.0092$, $\mathrm{P}=0.0014$ and $\mathrm{P}=0.0016)$ and $\mathrm{Cyclin} \mathrm{E}(\mathrm{P}<0.0001, \mathrm{P}=0.0002$ and $\mathrm{P}=0.0001$ ), while treatment increased the expression levels of Caspase-3 ( $\mathrm{P}=0.0001, \mathrm{P}<0.0001$ and $\mathrm{P}<0.0001)$, Caspase- 8 $(\mathrm{P}=0.0002, \mathrm{P}=0.0003$ and $\mathrm{P}=0.0006)$ and Caspase-9 $(\mathrm{P}=0.0003, \mathrm{P}<0.0001$ and $\mathrm{P}=0.0002)$ in $\mathrm{U} 251$ cells (Fig. $5 \mathrm{C}$ ). Therefore, the results suggested that miR-181d inhibited cell apoptosis via the IGF1/PI3K/AKT axis.

For the cell cycle-related proteins, the miR-181d mimic increased the expression levels of Ki67, IDH-1R, IGFBP2 and TERT ( $\mathrm{P}=0.0003,0.0103,0.0012$ and 0.0006 , respectively), but decreased the expression of PTEN $(\mathrm{P}<0.0001)$. However, the expression levels of Ki67 $(\mathrm{P}=0.0001, \mathrm{P}=0.0004$ and $\mathrm{P}=0.0001$, respectively), IDH-1R $(\mathrm{P}=0.0161, \mathrm{P}=0.0027$ and $\mathrm{P}=0.0019$, respectively), IGFBP2 $(\mathrm{P}=0.0003, \mathrm{P}=0.0092$ and $\mathrm{P}=0.0001$, respectively) and TERT $(\mathrm{P}=0.0030, \mathrm{P}=0.0005$ and $\mathrm{P}=0.0004$, respectively) were reduced by treatment with the IGF1, PI3K/AKT and miR-181d inhibitors, while PTEN expression was increased $(\mathrm{P}=0.0033, \mathrm{P}=0.0036$ and $\mathrm{P}=0.0030$, respectively; Fig. 5D).

\section{Discussion}

Glioma is a common brain tumor, most commonly caused by genetic abnormalities, with an incidence rate of 3-8 cases per 100,000 worldwide (2). Thus, it is important to investigate novel biomarkers that could be useful for the early diagnosis and treatment of glioma. miRNAs regulate gene expression and protein degradation by binding to the complementary DNA sequences on the 3 'untranslated regions of the target 
mRNAs $(7,8)$. A previous study reported that miR-181d mediated the proliferation, as well as promoted the maturation of dendritic cells (30). Moreover, the present results indicated that miR-181d promoted the expression of IGF1, cellular proliferation and the growth of glioma xenografts.

Ho et al (31) revealed that miR-181d was negatively correlated with the expression of IGF1 in glioma cells. In addition, Chen et al (32) demonstrated that the IGF1/PI3K/AKT pathway was involved in drug-induced cell progression in breast cancer. To investigate whether miR-181d regulated cellular progression via the IGF1/PI3K/AKT axis, the present study assessed cell proliferation, cell cycle progression and cellular apoptosis after treatment with IGF1, PI3K/AKT andmiR-181d inhibitors. Consistent with previous findings $(31,32)$, treatment with the IGF1 and PI3K/AKT inhibitors suppressed the proliferative ability and inhibited the PI3K/AKT/mTOR pathway in U251 cells. Zhang et al (33) reported that miR-181d promoted cell cycle progression in uveal melanoma. In line with this finding, the present results suggested that miR-181d promoted cell cycle progression, while treatment with IGF1 or PI3K/AKT inhibitors suppressed cell cycle progression in U251 cells. In addition, miR-181d mimic inhibited apoptosis while treatment with an IGF1 inhibitor and a PI3K/AKT inhibitor promoted apoptosis in U251 cells. A xenograft model was constructed to assess these results in vivo, and it was observed that the growth of glioma xenografts was improved by miR-181d mimic, while it was suppressed by treatment with IGF1 or PI3K/AKT inhibitors.

In conclusion, the present results indicated that miR-181d promoted cellular proliferation via the PI3K/AKT/mTOR signaling pathway in both U251 cells and xenograft tissues. Furthermore, miR-181d promoted cell cycle progression and suppressed apoptosis via the IGF1/PI3K/AKT axis in xenograft tissues derived from U251 cells. It was also demonstrated that miR-181d enhanced the growth of glioma xenografts in vivo.

\section{Acknowledgements}

Not applicable.

\section{Funding}

The current study was supported by grants from the National Natural Science Foundation of China (grant nos. 81572489 and 81372683) and the Hubei Province Health and Family Planning Scientific Research Project (grant no. WJ2007Q008).

\section{Availability of data and materials}

The datasets used and/or analyzed during the current study are available from the corresponding author on reasonable request.

\section{Authors' contributions}

QC and BL contributed to the conception of the study and analyzed the data. DT performed the experiments and wrote the manuscript. WG, JY and JL analyzed the data and wrote the manuscript. JZ and JG analyzed the data and provided constructive criticism. All authors read and approved the final manuscript.

\section{Ethics approval and consent to participate}

All animal experiments were approved by the Renmin Hospital of Wuhan University Animal Care and Use Committee (approval no. 20180908).

\section{Patient consent for publication}

Not applicable.

\section{Competing interests}

The authors declare that they have no competing interests.

\section{References}

1. Furnari FB, Fenton T, Bachoo RM, Mukasa A, Stommel JM, Stegh A, Hahn WC, Ligon KL, Louis DN, Brennan C, et al: Malignant astrocytic glioma: Genetics, biology, and paths to treatment. Genes Dev 21: 2683-2710, 2007.

2. Sayegh ET, Kaur G, Bloch O and Parsa AT: Systematic review of protein biomarkers of invasive behavior in glioblastoma. Mol Neurobiol 49: 1212-1244, 2014.

3. Jemal A, Bray F, Center MM, Ferlay J, Ward E and Forman D: Global cancer statistics. CA Cancer J Clin 61: 69-90, 2011.

4. Kim GW, Lee DH, Yeon SK, Jeon YH, Yoo J, Lee SW and Kwon SH: Temozolomide-resistant glioblastoma depends on HDAC6 activity through regulation of DNA mismatch repair. Anticancer Res 39: 6731-6741, 2019.

5. Linz U: Commentary on effects of radiotherapy with concomitant and adjuvant temozolomide versus radiotherapy alone on survival in glioblastoma in a randomised phase III study: 5-year analysis of the EORTC-NCIC trial (Lancet Oncol. 2009; 10: 459-466). 2009; 10: 459-466). Cancer 116: 1844-1846, 2010.

6. Stupp R, Mason WP, van den Bent MJ, Weller M, Fisher B, Taphoorn MJB, Belanger K, Brandes AA, Marosi C, Bogdahn U, et al: Radiotherapy plus concomitant and adjuvant temozolomide for glioblastoma. N Engl J Med 352: 987-996, 2005.

7. Lai EC: Micro RNAs are complementary to 3 'UTR sequence motifs that mediate negative post-transcriptional regulation. Nat Genet 30: 363-364, 2002.

8. Bartel DP: MicroRNAs: Genomics, biogenesis, mechanism, and function. Cell 116: 281-297, 2004.

9. Adams BD, Kasinski A and Slack FJ: Aberrant regulation and function of microRNAs in cancer. Curr Biol 24: R762-R776, 2014.

10. Cowland JB, Hother C and Grønbaek K: MicroRNAs and cancer. APMIS 115: 1090-1106, 2007.

11. Chen H, Liu T, Liu J, Feng Y, Wang B, Wang J, Bai J, Zhao W, Shen Y, Wang X, et al: Circ-ANAPC7 is upregulated in acute myeloid leukemia and appears to target the MiR-181 family. Cell Physiol Biochem 47: 1998-2007, 2018.

12. Xia S, Tian H, Fan L and Zheng J: Peripheral blood miR-181-5p serves as a marker for screening patients with osteoarthritis by targeting TNF $\alpha$. Clin Lab 63: 1819-1825, 2017.

13. Zhu W, Shan X, Wang T, Shu Y and Liu P: miR-181b modulates multidrug resistance by targeting BCL2 in human cancer cell lines. Int J Cancer 127: 2520-2529, 2010.

14. Guo X, Zhu Y, Hong X, Zhang M, Qiu X, Wang Z, Qi Z and Hong X: miR-181d and c-myc-mediated inhibition of CRY2 and FBXL3 reprograms metabolism in colorectal cancer. Cell Death Dis 8: e2958, 2017.

15. Wang XF, Shi ZM, Wang XR, Cao L, Wang YY, Zhang JX, Yin Y, Luo H, Kang CS, Liu N, et al: MiR-181d acts as a tumor suppressor in glioma by targeting K-ras and Bcl-2. J Cancer Res Clin Oncol 138: 573-584, 2012.

16. Zhang W, Zhang J, Hoadley K, Kushwaha D, Ramakrishnan V, Li S, Kang C, You Y, Jiang C, Song SW, et al: miR-181d: A predictive glioblastoma biomarker that downregulates MGMT expression. Neuro Oncol 14: 712-719, 2012. 
17. Chen YY, Ho HL, Lin SC, Ho TDH and Hsu CY: Upregulation of miR-125b, miR-181d, and miR-221 predicts poor prognosis in MGMT promoter-unmethylated glioblastoma patients. Am J Clin Pathol 149: 412-417, 2018.

18. Allard JB and Duan C: IGF-binding proteins: Why do they exist and why are there so many? Front Endocrinol (Lausanne) 9: 117, 2018.

19. Duan C, Ren H and Gao S: Insulin-like growth factors (IGFs), IGF receptors, and IGF-binding proteins: Roles in skeletal muscle growth and differentiation. Gen Comp Endocrinol 167: 344-351, 2010

20. Nielsen EM, Hansen L, Lajer M, Andersen KL, Echwald SM, Urhammer SA, Hansen T and Pedersen O: A common polymorphism in the promoter of the IGF-I gene associates with increased fasting serum triglyceride levels in glucose-tolerant subjects. Clin Biochem 37: 660-665, 2004.

21. Li Z, Pan W, Shen Y, Chen Z, Zhang L, Zhang Y, Luo Q and Ying X: IGF1/IGF1R and microRNA let-7e down-regulate each other and modulate proliferation and migration of colorectal cancer cells. Cell Cycle 17: 1212-1219, 2018.

22. Wang $\mathrm{H}$, Tang $\mathrm{C}$, Na M, Ma W, Jiang Z, Gu Y, Ma G, Ge H, Shen $\mathrm{H}$ and Lin Z: miR-422a inhibits glioma proliferation and invasion by targeting IGF1 and IGF1R. Oncol Res 25: 187-194, 2017.

23. LoRusso PM: Inhibition of the PI3K/AKT/mTOR pathway in solid tumors. J Clin Oncol 34: 3803-3815, 2016.

24. Chen B, Xue Z, Yang G, Shi B, Yang B, Yan Y, Wang X, Han D, Huang Y and Dong W: Akt-signal integration is involved in the differentiation of embryonal carcinoma cells. PLoS One 8 : e64877, 2013.

25. Saiki S, Sasazawa Y, Imamichi Y, Kawajiri S, Fujimaki T, Tanida I, Kobayashi H, Sato F, Sato S, Ishikawa KI, et al: Caffeine induces apoptosis by enhancement of autophagy via PI3K/Akt/mTOR/p70S6K inhibition. Autophagy 7: 176-187, 2011.

26. Liu G, Zhao X, Zhou J, Cheng X, Ye Z and Ji Z: LncRNA TP73-AS1 promotes cell proliferation and inhibits cell apoptosis in clear cell renal cell carcinoma through repressing KISS 1 expression and inactivation of PI3K/Akt/mTOR signaling pathway. Cell Physiol Biochem 48: 371-384, 2018.
27. Ye R, Dai N, He Q, Guo P, Xiang Y, Zhang Q, Hong Z and Zhang Q: Comprehensive anti-tumor effect of Brusatol through inhibition of cell viability and promotion of apoptosis caused by autophagy via the PI3K/Akt/mTOR pathway in hepatocellular carcinoma. Biomed Pharmacother 105: 962-973, 2018.

28. Dai Z, Wang L, Wang X, Zhao B, Zhao W, Bhardwaj SS, Ye J, Yin Z, Zhang J and Zhao S: Oxymatrine induces cell cycle arrest and apoptosis and suppresses the invasion of human glioblastoma cells through the EGFR/PI3K/Akt/mTOR signaling pathway and STAT3. Oncol Rep 40: 867-876, 2018.

29. National Research Council (US) Committee on Recognition and Alleviation of Pain in Laboratory Animals: Recognition and alleviation of pain in laboratory animals. Washington (DC): National Academies Press (US), 2009.

30. Su XW, Lu G, Leung CK, Liu Q, Li Y, Tsang KS, Zhao SD, Chan DTM, Kung HF and Poon WS: miR-181d regulates human dendritic cell maturation through NF- $\kappa$ B pathway. Cell Prolif 50: e12358, 2017.

31. Ho KH, Chen PH, His E, Shih CM, Chang WC, Cheng $\mathrm{CH}$, Lin CW and Chen KC: Identification of IGF-1-enhanced cytokine expressions targeted by miR-181d in glioblastomas via an integrative miRNA/mRNA regulatory network analysis. Sci Rep 7: 732, 2017.

32. Chen J,Zeng J, Xin M,Huang W and Chen X: Formononetin induces cell cycle arrest of human breast cancer cells via IGF1/PI3K/Akt pathways in vitro and in vivo. Horm Metab Res 43: 681-686, 2011.

33. Zhang L, He X, Li F, Pan H, Huang X, Wen X, Zhang H, Li B, Ge S, Xu X, et al: The miR-181 family promotes cell cycle by targeting CTDSPL, a phosphatase-like tumor suppressor in uveal melanoma. J Exp Clin Cancer Res 37: 15, 2018.

This work is licensed under a Creative Commons Attribution-NonCommercial-NoDerivatives 4.0 International (CC BY-NC-ND 4.0) License. 